Bull. Egypt. Soc. Physiol. Sci. 40 (1), 148-165

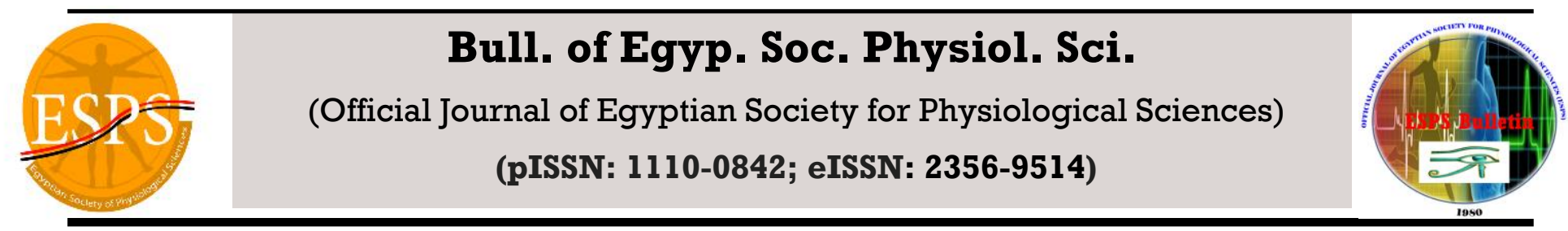

\title{
Sex Differences in Metabolic Responses to Chronic Immobilization Stress in Rats
}

\author{
Ienass Mohamed Bahaa El-Dein ${ }^{1}$, Fatma A. Mohamed ${ }^{1}$,Mona A. Ahmed ${ }^{1}$, Nevine \\ Bahaa E. Soliman ${ }^{2}$, Noha N. Lasheen ${ }^{1}$, Doaa A. Abou-Bakr ${ }^{1}$ \\ 1: Physiology Department, Faculty of Medicine, Ain Shams University, Egypt \\ 2: Histology Department, Faculty of Medicine, Ain Shams University, Egypt
}

Received: 27 Oct 2019

Accepted: 25 Nov 2019

Available online: 1 Jan 2020

Keywords

- Gender

- Immobilization stress

- Metabolic disorders

- Oxidative stress

- Sex hormones

\section{Abstract}

Background: Responses to stress could range from homeostatic variations to lifethreatening effects. Gender is accompanied by variations in oxidative stress that are implicated in the development of metabolic diseases. Females were found to be less susceptible to oxidative stress. Aim: to clarify the differences in metabolic responses to chronic immobilization stress in both rat sexes, and to elucidate the possible underlying mechanism(s). Methods: 40 adult albino rats of both sexes were divided into 2 main groups: control and stressed groups, each was subdivided into male and female groups. Stressed groups were exposed to immobilization for 4 weeks. All rats were subjected to estimation of body mass index percentage change (BMI\%), visceral fat weight (VFW), glycemic parameters, lipid profile, plasma insulin, leptin, sex hormones, malondialdehyde (MDA), total antioxidant capacity (TAC) and nitrite. HOMA-B and HOMA-IR were calculated, Caspase-3 was assessed in pancreas by immunohistochemistry. Results: Stressed male rats showed lower BMI\%, VFW, dyslipidemia, hyperglycemia, higher glucose output by kidneys, lower glucose uptake by diaphragm, HOMA-B, plasma insulin, testosterone and TAC, with higher plasma estrogen and MDA levels compared to control male group. Compared to control females, stressed females exhibited lower VFW, hyperglycemia, hypoinsulinemia, dyslipidemia, lower plasma TAC and HOMA-B, with higher nitrite and sex hormones. Compared to stressed males, stressed females showed higher BMI\%, plasma TAC and estrogen, but lower glucose output by kidneys, dyslipidemia and testosterone. Conclusion: Chronic immobilization stress imposes greater metabolic derangement in males than in females. The altered sex hormones and lowered antioxidants could be contributory mechanisms. 


\section{INTRODUCTION}

Priyadarshin and Aich ${ }^{(1)}$ defined stress as a process which allows an organism to accommodate for the demands of its environment to be adapted to its conditions safely. Stress was reported to cause distorted homeostatic functions in the organism as a result of a stressor, which could be a physiological or psychological challenge $^{(2)}$. In frequent stress exposure, lack of coping, inadequate stress responses and stimulated compensatory mechanisms could occur ${ }^{(I)}$. Sandifer et $a l .{ }^{(3)}$ stated that the allostatic load could explain how stress responses might be pathological and destructive to the human body. Also, the allostatic load might become overwhelming and the adaptive processes could be maladaptive and harmful to the body ${ }^{(4)}$.

Further, Pitocco et $a .^{(5)}$ reported that the imbalance in reactive oxygen species (ROS) and reactive nitrogen species (RNS) production could disturb homeostasis. ROS had been reported to be the causative factor of many critical conditions such as aging and cancer $^{(\boldsymbol{( b )}}$, atherosclerosis ${ }^{(7)}$, obesity and diabetes ${ }^{(8)}$, and neurodegenerative diseases ${ }^{(9)}$. Pitocco et al. ${ }^{(5)}$ added that ROS could cause irreversible changes of cellular constituents such as proteins, lipids, or DNA.

Furthermore, Verma et al. ${ }^{(10)}$ stated that stress response could be varied in males and females, because men and women could react in different ways to stress in both psychological and biological aspects. Ahmed ${ }^{(11)}$ reported that testosterone protected the pancreas from tissue damage and conserved B-cell dysfunction, also, enhanced insulin secretion and abolished oxidative stress induced by stress.
Therefore, this study was conducted to clarify the sex differences in the metabolic responses to chronic immobilization stress in rats, and to elucidate the possibility of involvement of sex hormones and oxidative stress as underlying explanatory mechanisms.

\section{Materials and Methods:}

This study was performed on 40 adult albino Wister rats of both sexes aged 12 months; initially weighing 200-300 g. Rats were purchased from a rat farm in Giza, and maintained in Medical Ain Shams Research Institute (MASRI) under standard conditions of boarding. Rats were fed regular diet composed of bread, milk and vegetables, with free access to water. Animals were not exposed to unnecessary pain or stress and animal manipulation was performed with maximal care and hygiene. At the end of experiment, animals were killed by overdose of anesthesia. Animal remains were disposed by incineration. The study was approved by the Research Ethics Committee 0000175785, Faculty of Medicine Ain Shams University (2015). Rats were randomly allocated into the following groups:

Group I: Control group, which was further subdivided into:

1-Control male group $(n=10)$.

2-Control female group $(n=10)$.

Rats in these 2 subgroups were maintained under the standard conditions of boarding until sacrificed.

Group II: Stressed group, which was further subdivided into:

1-Stressed male group $(n=10)$.

2-Stressed female group $(n=10)$. 
Rats in these 2 groups were subjected to immobilization stress by being encaged 2 hours daily, with cage dimensions of $6 \mathrm{~cm} \times 8 \mathrm{~cm} \times 14 \mathrm{~cm}$, 5 days/week, for 4 weeks, as described by Diab ${ }^{(12)}$.

\section{Experimental Procedures:}

At the end of the experimental period (4 weeks), overnight fasted rats were weighed and anaesthetized by intraperitoneal injection of thiopental sodium (Sigma tec Pharmaceutical industries), in a dose of $40 \mathrm{mg} / \mathrm{Kg} \mathrm{B}$.W. The nasoanal length and the waist circumference were measured, and a blood sample was collected thereafter from abdominal aorta in a tube containing heparin and centrifuged at $3000 \mathrm{rpm}$ for $15 \mathrm{~min}$. An aliquot of the separated plasma was immediately used for determination of plasma glucose, and the remaining plasma was divided into small aliquots that were stored frozen at $-80^{\circ} \mathrm{C}$ for the biochemical studies.

Immediately after blood sample collection, the abdominal incision was extended upward to open the thoracic cage, and the diaphragm was quickly and carefully excised, and placed in iced Krebs solution for 10 minutes to be used for the in vitro determination of glucose uptake by the diaphragm. Then, both kidneys were dissected out, immediately placed in iced Krebs-Ringer solution to be used in determination of glucose output by the kidneys. Visceral fat as well as the liver and pancreas were taken out and weighed. All the following parameters were assessed in all the studied groups:

Anthropometric Measures: The initial and final body weight (g.) and naso-anal length $(\mathrm{cm})$ were used to determine initial and final body mass index
(BMI) according to Nascimento et al. $^{(13)}$, as follows:

$$
\text { BMI= body weight }(\mathrm{g}) / \text { length }{ }^{2}\left(\mathrm{~cm}^{2}\right) .
$$

Then, BMI percentage change (BMI\%) was calculated as follows:

BMI\% = (Final BMI-Initial BMI)/Initial BMI X 100

Relative weight (RW) of liver and pancreas were calculated as follows:

$\mathbf{R W}=$ AW (absolute organ weight) /BW (body weight) X 100

Biochemical Studies: Plasma glucose was determined according to Trinder ${ }^{(14)}$ using kits supplied by Stanbio (USA). Lipid profile, plasma levels of malondialdehyde (MDA), total antioxidant capacity (TAC) and nitrite were determined by colorimetric methods using kits supplied by Biodiagnostics (Egypt). Plasma insulin and leptin were measured by ELISA techniques using kits supplied by DRG instruments (USA). In addition, plasma testosterone and estradiol levels were measured by competitive immunoenzymatic colorimetric method using kits supplied by Novatec Immunodiagnostica GmbH (Germany).

\section{High density lipoprotein-cholesterol (HDL-C):} was calculated according to Friedewald et al. ${ }^{(15)}$ from the formula:

$$
\text { HDL-C }(\mathbf{m g} / \mathbf{d l})=\mathrm{TC}-(\mathrm{LDL}-\mathrm{C}+\mathrm{Tg} / 5)
$$

Atherogenic index (AI): was calculated according to Malaspina et al. ${ }^{(\mathbf{1 6})}$ from the formula:

$$
\mathbf{A} \mathbf{I}=\mathrm{TC} / \mathrm{HDL}-\mathrm{C}
$$


Homeostatic Model Assessment: HOMA-IR (Insulin Resistance) and HOMA-B (Beta cell function): were calculated according to Matthews et al. ${ }^{(17)}$, as follows:

HOMA-IR= Fasting insulin $\times$ Fasting glucose $/$ 405

HOMA-B $=360 *$ [Fasting Insulin] / ([Fasting Glucose] - 63) \%

Biological Studies: Glucose uptake by diaphragm was determined as described by Saleh and Saleh $^{(18)}$. Glucose output by both kidneys was determined as described by Randall ${ }^{(19)}$.

Histopathological study: Pancreas was dissected and preserved in $10 \%$ formaline for study of Caspase-3 immunohistochemistry that was performed as described by Suvarna et al. ${ }^{(20)}$.

\section{Statistical analysis:}

Data represented as Mean \pm SEM. Statistical data and significance were performed by using SPSS version 20. One way ANOVA was used to compare between the different groups with least significant difference test (LSD) to find intergroupal significance. $\mathrm{P}$ value $<0.05$ was considered statistically significant.

\section{Results:}

Compared to the control male group, stressed male rats showed significantly decreased BMI\% and visceral fat weight (VFW) and significantly increased relative liver weight (RLW) (table 1). Stressed males, also, showed significantly increased fasting plasma glucose and glucose output by kidneys, while the glucose uptake by diaphragm was significantly decreased, as in (table2). Plasma Tg, TC, LDL-C and atherogenic index were all significantly increased in stressed male group, while HDL-C was significantly decreased denoting dyslipidemic lipid profile (table 3). Plasma MDA level was significantly increased in stressed males while plasma TAC showed significant decline denoting occurrence of oxidative stress, as shown in (table 4). Plasma insulin and testosterone were significantly decreased, while plasma estrogen was significantly increased in stressed males, as shown in (table 5). HOMA-B showed significant reduction denoting pancreatic B-cell affection in male rats exposed to stress (table 6).

Compared to control female group, stressed female group exhibited significantly reduced VFW (table 1), but significantly higher fasting plasma glucose level, plasma levels of TC, LDL-C, and atherogenic index (tables 2\&3). They, also, showed significantly reduced plasma TAC accompanied by significantly elevated nitrite levels (table 4). In addition, plasma levels of estrogen and testosterone were significantly elevated, while a significant decline in plasma insulin level and HOMA-B were observed in stressed female group compared to control female group (tables 5\&6).

Regarding sex difference, control female rats exhibited significantly lower BMI\%, plasma levels of TC, HDL-C and testosterone, accompanied by significantly elevated plasma levels of MDA, TAC and estrogen compared to the respective control male rats. Compared to stressed male rats, stressed female rats had significantly lower ALW, glucose output by kidneys and plasma levels of $\mathrm{Tg}$, TC, atherogenic index and significantly reduced plasma testosterone. Stressed females, also, 
showed significantly higher BMI\%, plasma levels of TAC and estrogen, compared to stressed male rats (tables 1-6).

Caspase-3 immuno-stained pancreas of control male and female rats, showed negligible Caspase-3 immunoreactivity in the islets of Langerhans and acinar cells of pancreas, with no apparent difference between both groups, with Caspase-3 area $\%$ was insignificantly different. Stressed male rats showed numerous Caspase-3 immuno-positive islet cells and pancreatic acinar cells, with Caspase-3 area \% was significantly elevated compared to control male group. Stressed female rats, showed the presence of multiple Caspase-3 immuno-positive cells in the islets and acini, with Caspase-3 area \% was significantly higher in this group compared to control female rats, as shown in (figure1) and (table 7).

Table (1): Body mass index percentage change (BMI, \%), waist circumference (WC, cm), visceral fat weight (VFW, gm), absolute and relative liver weight (ALW, gm; RLW, \%) and absolute and relative pancreas weight (APW, gm; RPW, \%) in the studied groups.

\begin{tabular}{|c|c|c|c|c|c|c|c|c|c|c|c|c|c|c|}
\hline \multirow{2}{*}{$\begin{array}{l}\text { Experimental } \\
\text { groups }\end{array}$} & \multicolumn{7}{|c|}{ Male } & \multicolumn{7}{|c|}{ Female } \\
\hline & BMI\% & WC & VFW & $\overline{\mathbf{A L W}}$ & RLW & APW & RPW & BMI\% & WC & VFW & ALW & RLW & $\overline{\mathbf{A P W}}$ & RPW \\
\hline Control & 14.69 & 14.60 & 2.87 & 6.81 & 2.34 & 0.642 & 0.221 & 5.86 & 14.15 & 3.36 & 6.40 & 2.57 & 0.477 & 0.194 \\
\hline $\begin{array}{c}\text { Group } \\
\text { P* }\end{array}$ & \pm 2.203 & $\pm \mathbf{0 . 3 1 0}$ & \pm 0.380 & \pm 0.470 & \pm 0.110 & \pm 0.060 & \pm 0.025 & $\begin{array}{l} \pm 1.52 \\
<0.005\end{array}$ & $\begin{array}{c} \pm 0.21 \\
\text { NS }\end{array}$ & $\begin{array}{c} \pm 0.701 \\
\text { NS }\end{array}$ & $\begin{array}{c} \pm 0.40 \\
\text { NS }\end{array}$ & $\begin{array}{c} \pm 0.140 \\
\text { NS }\end{array}$ & $\begin{array}{c} \pm 0.056 \\
\mathrm{NS}\end{array}$ & $\begin{array}{c} \pm 0.025 \\
\text { NS }\end{array}$ \\
\hline $\begin{array}{c}\text { Stressed } \\
\text { group }\end{array}$ & $\begin{array}{l}-1.520 \\
\pm 1.374\end{array}$ & $\begin{array}{c}14.50 \\
\pm 0.380\end{array}$ & $\begin{array}{c}1.12 \\
\pm 0.310\end{array}$ & $\begin{array}{c}7.66 \\
\pm 0.630\end{array}$ & \begin{tabular}{|c|}
3.03 \\
\pm 0.290 \\
\end{tabular} & $\begin{array}{c}0.565 \\
\pm 0.072\end{array}$ & $\begin{array}{c}0.222 \\
\pm 0.027\end{array}$ & \begin{tabular}{|c|}
3.99 \\
\pm 1.29 \\
\end{tabular} & \begin{tabular}{|c|}
13.95 \\
\pm 0.160
\end{tabular} & $\begin{array}{c}1.84 \\
\pm 0.400\end{array}$ & $\begin{array}{c}6.21 \\
\pm 0.200\end{array}$ & $\begin{array}{c}2.44 \\
\pm 0.110\end{array}$ & $\begin{array}{c}0.576 \\
\pm 0.078 \\
\end{array}$ & $\begin{array}{c}0.224 \\
\pm 0.028\end{array}$ \\
\hline $\begin{array}{l}\text { P* } \\
\text { P1 }\end{array}$ & $<0.001$ & NS & $<0.001$ & NS & $<0.05$ & NS & NS & $\begin{array}{c}<0.01 \\
\text { NS }\end{array}$ & $\begin{array}{l}\text { NS } \\
\text { NS }\end{array}$ & $\begin{array}{c}\mathrm{NS} \\
<0.02\end{array}$ & $\begin{array}{c}<0.05 \\
\text { NS }\end{array}$ & $\begin{array}{l}\text { NS } \\
\text { NS }\end{array}$ & $\begin{array}{l}\text { NS } \\
\text { NS }\end{array}$ & $\begin{array}{l}\text { NS } \\
\text { NS }\end{array}$ \\
\hline
\end{tabular}

Values are expressed as mean \pm SEM. $\mathbf{P *}$ : Significance calculated by LSD at $\mathrm{P}<0.05$ from respective male group. P1: Significance calculated by LSD at $\mathrm{P}<0.05$ from respective male or female control group. NS: Not significant.

Table (2): Fasting plasma glucose level (mg/dl), glucose uptake by diaphragm (mg/100ml/g/90 min) and glucose output by kidneys $(\mathrm{mg} / \mathrm{g} / 60 \mathrm{~min})$ in the studied groups.

\begin{tabular}{|c|c|c|c|c|c|c|}
\hline \multirow[b]{2}{*}{$\begin{array}{c}\text { Experimental } \\
\text { groups }\end{array}$} & \multicolumn{3}{|c|}{ Male } & \multicolumn{3}{|c|}{ Female } \\
\hline & $\begin{array}{l}\text { Fasting } \\
\text { plasma } \\
\text { glucose }\end{array}$ & $\begin{array}{c}\text { Glucose } \\
\text { Uptake by } \\
\text { diaphragm }\end{array}$ & $\begin{array}{c}\text { Glucose } \\
\text { output by } \\
\text { kidneys }\end{array}$ & $\begin{array}{l}\text { Fasting } \\
\text { plasma } \\
\text { glucose }\end{array}$ & $\begin{array}{c}\text { Glucose } \\
\text { uptake by } \\
\text { diaphragm }\end{array}$ & $\begin{array}{l}\text { Glucose } \\
\text { output by } \\
\text { kidneys }\end{array}$ \\
\hline Control & 99.62 & 105.2 & 20.85 & 98.66 & 88.74 & 15.88 \\
\hline Group & \pm 2.92 & \pm 13.50 & \pm 3.21 & \pm 4.89 & \pm 16.72 & \pm 8.40 \\
\hline $\mathbf{P}^{*}$ & & & & NS & NS & NS \\
\hline Stressed & 195.32 & 34.11 & 119.36 & 144.69 & 52.31 & 24.48 \\
\hline Group & \pm 26.33 & \pm 8.00 & \pm 31.08 & \pm 13.43 & \pm 6.28 & \pm 6.19 \\
\hline $\mathbf{P}^{*}$ & & & & NS & NS & $<0.02$ \\
\hline P1 & $<0.001$ & $<0.002$ & $<0.001$ & $<0.001$ & NS & NS \\
\hline
\end{tabular}

Values are expressed as mean \pm SEM. P*: Significance calculated by LSD at P $<0.05$ from respective male group. P1: Significance calculated by LSD at $\mathrm{P}<0.05$ from respective male or female control group. NS: Not significant. 
Table (3): Plasma triglycerides ( $\mathrm{Tg}, \mathrm{mg} / \mathrm{dl}$ ), total cholesterol (TC, mg/dl), low density lipoprotein (LDL-C, $\mathrm{mg} / \mathrm{dl}$ ), high density lipoprotein (HDL-C, mg/dl) and atherogenic index (AI) in the studied groups.

\begin{tabular}{|c|c|c|c|c|c|c|c|c|c|c|}
\hline \multirow{2}{*}{$\begin{array}{c}\text { Experimental } \\
\text { groups }\end{array}$} & \multicolumn{5}{|c|}{ Male } & \multicolumn{5}{|c|}{ Female } \\
\hline & Tg & TC & LDL-C & HDL-C & AI & $\mathrm{Tg}$ & TC & LDL-C & HDL-C & AI \\
\hline Control & 27.08 & \begin{tabular}{|l|}
56.15 \\
\end{tabular} & 20.22 & 30.52 & 1.88 & \begin{tabular}{|l|}
23.98 \\
\end{tabular} & 48.80 & 19.71 & 24.30 & 2.05 \\
\hline group & \pm 1.72 & \pm 1.78 & \pm 0.566 & \pm 1.87 & \pm 0.069 & \pm 1.64 & \pm 1.70 & \pm 0.448 & \pm 1.52 & \pm 0.071 \\
\hline $\mathbf{P}^{*}$ & & & & & & NS & $<0.01$ & NS & $<0.02$ & NS \\
\hline Stressed & 45.78 & 101.69 & 62.92 & 20.82 & 4.72 & 28.58 & 75.08 & 45.82 & 23.54 & 3.27 \\
\hline group & $\pm \mathbf{3 . 3 8}$ & \pm 8.92 & \pm 7.09 & \pm 2.51 & \pm 0.503 & \pm 2.25 & \pm 4.92 & \pm 5.02 & \pm 1.10 & \pm 0.281 \\
\hline $\mathbf{P} *$ & & & & & & $<0.001$ & $<0.02$ & NS & NS & $<0.02$ \\
\hline P1 & 00 & 00 & .001 & $<0.005$ & .00 & $\mathbf{S}$ & $<0.001$ & $<0.001$ & NS & $<0.002$ \\
\hline
\end{tabular}

Values are expressed as mean \pm SEM. P*: Significance calculated by LSD at $\mathrm{P}<0.05$ from respective male group. P1: Significance calculated by LSD at $\mathrm{P}<0.05$ from respective male or female control group. NS: Not significant.

Table (4): Plasma malondialdehyde (MDA, $\mathrm{nmol} / \mathrm{ml}$ ), total antioxidant capacity (TAC, $\mathrm{mM} / \mathrm{l})$ and nitrite $(\mu \mathrm{mol} / \mathrm{l})$ levels in the studied groups.

\begin{tabular}{|c|c|c|c|c|c|c|}
\hline \multirow{2}{*}{$\begin{array}{l}\text { Experimental } \\
\text { groups }\end{array}$} & \multicolumn{3}{|c|}{ Male } & \multicolumn{3}{|c|}{ Female } \\
\hline & MDA & TAC & Nitrite & MDA & TAC & Nitrite \\
\hline Control & 2.12 & 7.14 & 33.61 & 2.73 & 7.46 & 30.15 \\
\hline Group & \pm 0.076 & \pm 0.1 & \pm 1.97 & \pm 0.172 & \pm 0.108 & \pm 0.78 \\
\hline $\mathbf{P}^{*}$ & & & & $<0.01$ & $<0.05$ & NS \\
\hline Stressed & 4.14 & 5.67 & 37.24 & 3.22 & 6.82 & 33.78 \\
\hline group & \pm 0.433 & \pm 0.430 & \pm 2.61 & \pm 0.208 & \pm 0.206 & \pm 1.29 \\
\hline $\mathbf{P}^{*}$ & & & & NS & $<0.05$ & NS \\
\hline P1 & $<0.001$ & $<0.002$ & NS & NS & $<0.02$ & $<0.05$ \\
\hline
\end{tabular}

Values are expressed as mean \pm SEM. P*: Significance calculated by LSD at $\mathrm{P}<0.05$ from respective male group. P1: Significance calculated by LSD at $\mathrm{P}<0.05$ from respective male or female control group. NS: Not significant.

Table (5): Plasma insulin $(\mu \mathrm{lU} / \mathrm{ml})$, leptin $(\mathrm{pg} / \mathrm{ml})$, testosterone $(\mathrm{pg} / \mathrm{ml})$ and estrogen $(\mathrm{pg} / \mathrm{ml})$ levels in the studied groups.

\begin{tabular}{|c|c|c|c|c|c|c|c|c|}
\hline \multirow{2}{*}{$\begin{array}{c}\text { Experimenta } \\
\text { groups }\end{array}$} & \multicolumn{4}{|c|}{ Male } & \multicolumn{4}{|c|}{ Female } \\
\hline & Insulin & Leptin & Testosterone & Estrogen & Insulin & Leptin & Testosterone & Estrogen \\
\hline Control & 13.15 & 0.132 & 3.81 & 18.17 & 10.75 & 0.157 & 0.042 & 72.72 \\
\hline group & & & & & \pm 1.15 & \pm 0.049 & \pm 0.006 & \pm 4.40 \\
\hline $\mathrm{P}^{*}$ & & & & & NS & NS & $<0.001$ & $<0.001$ \\
\hline Stressed & 7.91 & 0.106 & 0.865 & 71.59 & 5.62 & 0.058 & 0.191 & 387.58 \\
\hline group & \pm 1.52 & \pm 0.024 & \pm 0.074 & \pm 4.3 & \pm 1.26 & \pm 0.019 & \pm 0.021 & \pm 95.79 \\
\hline P* & & & & & NS & NS & $<0.001$ & $<0.002$ \\
\hline P1 & $<0.05$ & NS & $<0.001$ & $<0.001$ & $\mid<0.005$ & NS & $<0.001$ & $<0.001$ \\
\hline
\end{tabular}

Values are expressed as mean \pm SEM. P*: Significance calculated by LSD at $\mathrm{P}<0.05$ from respective male group. P1: Significance calculated by LSD at $\mathrm{P}<0.05$ from respective male or female control group. NS: Not significant. 
Table (6): Homeostatic model assessment of beta cell function (HOMA-B) and homeostatic model assessment of insulin resistance (HOMA- IR) in the studied groups.

\begin{tabular}{|c|c|c|c|c|}
\hline \multirow{2}{*}{$\begin{array}{c}\text { Experimental } \\
\text { groups }\end{array}$} & \multicolumn{2}{|c|}{ Male } & \multicolumn{2}{|c|}{ Female } \\
\hline & HOMA-B & HOMA-IR & HOMA-B & HOMA-IR \\
\hline $\begin{array}{l}\text { Control } \\
\text { group }\end{array}$ & $\begin{array}{l}\mathbf{1 3 8 . 9 9} \\
\pm 28.18\end{array}$ & $\begin{array}{c}3.23 \\
\pm 0.548\end{array}$ & $\begin{array}{c}219.93 \\
\pm 109.69\end{array}$ & $\begin{array}{c}2.54 \\
\pm 0.293\end{array}$ \\
\hline $\mathbf{P}^{*}$ & & & NS & NS \\
\hline $\begin{array}{c}\text { Stressed } \\
\text { group }\end{array}$ & $\begin{array}{c}33.63 \\
\pm 10.04\end{array}$ & $\begin{array}{c}3.09 \\
\pm 0.761\end{array}$ & $\begin{array}{l}29.48 \\
\pm 7.11\end{array}$ & $\begin{array}{c}2.02 \\
\pm \mathbf{0 . 5 7 3}\end{array}$ \\
\hline $\begin{array}{l}\text { P* } \\
\text { P1 }\end{array}$ & $<0.01$ & NS & $\underset{<0.05}{\mathrm{NS}}$ & $\begin{array}{l}\text { NS } \\
\text { NS }\end{array}$ \\
\hline
\end{tabular}

Values are expressed as mean \pm SEM. $\mathbf{P} *$ : Significance calculated by LSD at $\mathrm{P}<0.05$ from respective male group. P1: Significance calculated by LSD at $\mathrm{P}<0.05$ from respective male or female control group. NS: Not significant.
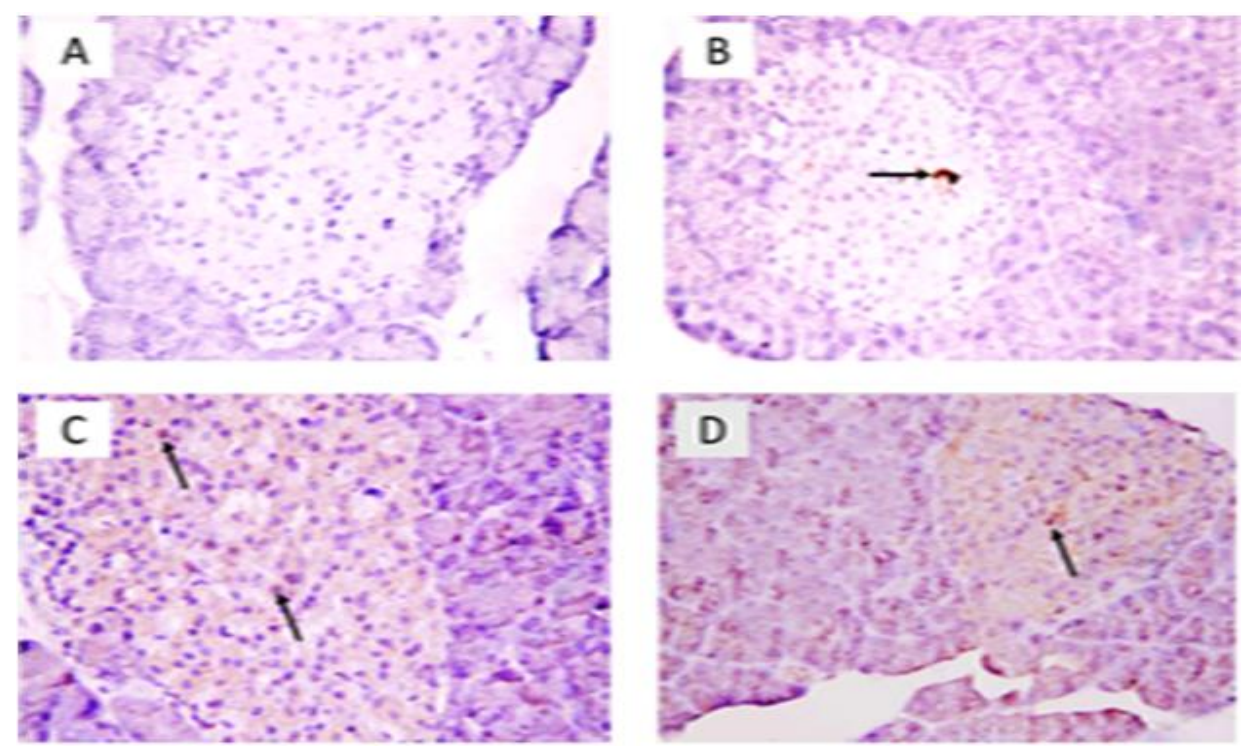

Figure (1): Photomicrographs of rat pancreas showing caspase 3 immunoreactivity in the cells of islets of Langerhans and in acinar cells of different groups (Avidine-Biotin immunoperoxidase technique $\mathrm{x}$ 400). (A, B) control groups of male and female rats respectively showing minimal caspase 3 immunoreactive cells $(\uparrow)$. (C) Stressed male group showing numerous caspase 3 immunoreactive cells $(\uparrow)$ (D) Stressed female group showing multiple caspase 3 immunoreactive cells $(\uparrow)$.

Table (7): Area \% of Caspase-3 immunopositive cells in islets of Langerhans in studied groups.

\begin{tabular}{|c|c|c|}
\hline $\begin{array}{c}\text { Experimental } \\
\text { groups }\end{array}$ & $\begin{array}{c}\text { Male } \\
\text { Caspase 3 area } \%\end{array}$ & $\begin{array}{c}\text { Female } \\
\text { Caspase 3 area \% }\end{array}$ \\
\hline Control & $\mathbf{0 . 2 9}$ & $\mathbf{0 . 3 3}$ \\
group & $\pm \mathbf{0 . 0 1 0}$ & $\mathbf{0 . 0 1 3}$ \\
& & $\mathbf{N S}$ \\
\hline P* & & $\mathbf{2 . 2 0}$ \\
Stressed & $\mathbf{2 . 2 3}$ & $\mathbf{0 . 0 6 0}$ \\
group & $\pm \mathbf{0 . 0 6 3}$ & $\mathbf{N S}$ \\
$\mathrm{P}^{*}$ & & $<\mathbf{0 . 0 0 1}$ \\
$\mathrm{P1}$ & $<\mathbf{0 . 0 0 1}$ & \\
\hline
\end{tabular}

Values are expressed as mean \pm SEM. P*: Significance calculated by LSD at P $<0.05$ from respective male group. P1: Significance calculated by LSD at $\mathrm{P}<0.05$ from respective male or female control group. NS: Not significant. 


\section{Discussion}

The present work was done to elucidate the difference between both male and female rats response to the effect of stress on glycemic and lipidemic status in an attempt to clarify the underlying mechanisms.

Both male and female stressed rats displayed reduction in their plasma insulin. This could be implicated in the low BMI\% and VFW as well as dyslipidemia observed in both sexes upon exposure to stress. The reduced insulin level on exposure to stress is in agreement with the study of Macfarlane et al. ${ }^{(21)}$ which reported that endogenous glucocorticoids constitutes a fundamental component of stress response and suppresses the insulin secretion relative to the level of hyperglycaemia and reduces the basal pulsatility of insulin secretion.

In addition, the low insulin plasma level in stressed groups could be attributed to oxidative stress which was found to cause gene expression changes, leading to impaired insulin secretion and increased apoptosis of pancreatic beta cell ${ }^{(22)}$. The significant decrease in HOMA-B observed in the present study in stressed groups of both sexes indicates pancreatic $\beta$-cell dysfunction, which could provide explanation for the low insulin level. This pancreatic dysfunction could be attributed to pancreatic cell injury in the form of apoptosis as denoted by significantly increased Caspase-3 area\%.

The pancreatic cells injury is suggested to be induced by oxidative stress as well as testosterone deficiency especially in stressed male rat group. This explanation is in accordance to the study by Ahmed $^{(11)}$ in which pancreatic degenerative and inflammatory changes and Caspase-3 were significantly positively correlated with MDA and significantly negatively correlated with testosterone and upon testosterone administration to stressed rats, the degenerative and inflammatory changes of the pancreatic tissue as well as the high MDA level were reversed.

Bardini et al. ${ }^{(23)}$ reported that increased free fatty acids (FFA), causes elevation of gluconeogenesis by the liver, shifting metabolism in muscles from glucose to lipid and lipotoxicity of beta-cell. $\mathrm{He}$ also suggested that cholesterol homeostasis is important for appropriate insulin secretion by beta-cells. Cholesterol accumulation in beta-cells caused by reduced cholesterol efflux secondary to defective HDL-C resulted in beta-cell apoptosis, defective insulin secretion and hyperglycemia. Hence, there is a reciprocal relationship between dyslipidemia and beta-cell dysfunction.

The low BMI\% and VFW as well as dyslipidemia could, also, be explained by the effect of stress hormones (catecholamines and cortisol) according to the study of Rabasa and Dickson $^{(24)}$ which mentioned that stress hormones cause mobilization of lipids into the circulation to support the "fight or flight" response. During stress, lipids are oxidized for energy production, then the released glycerol is used for gluconeogenesis, this effect was induced by the action of catecholamines that increase adipose triglyceride lipase and hormone sensitive lipase expression, activate hormone-sensitive lipase by its phosphorylation, with phosphorylation of perilipin proteins that conformationaly changed, this permit lipases to contact directly with lipid droplets, so increasing rate of lipolysis ${ }^{(25)}$. Norepinephrine-induced lipolysis was found to be 
mediated directly by stimulation of adipose tissue beta receptors, and indirectly by reducing insulin level, also, norepinephrine decreases lipase activity in the liver, increasing the plasma levels of VLDL, IDL, and $\mathrm{LDL}^{(26)}$.

Moreover, the elevated cortisol level accompanying stress, also, increases serum FFA, glycerol, and lipolysis allover body ${ }^{(27)}$. The increased supply of FFA by the adipose tissue through lipolysis increases liver production of VLDL during stress ${ }^{(28)}$. VLDL particles rich in triglycerides are circulated then converted to lipoproteins rich in cholesterol $^{(29)}$. Brindley et $a l{ }^{(28)}$ reported that phosphatidate phosphohydrolase is stimulated by cortisol, catecholamines, and glucagon, causing elevated synthesis of $\mathrm{Tg}$ by the liver. Also, HMG-CoA reductase is stimulated by glucocorticoids and FFA in the liver, increasing synthesis of cholesterol $^{(26)}$.

In stressed male, the significant reduction in plasma testosterone can be an additional cause for the dyslipidemia. This explanation is in consistence with epidemiological data suggesting that testosterone levels are negatively associated with Tg, TC and LDL-C and positively with HDL$\mathrm{C}$ as reported by Haffner et al. ${ }^{(30)}$. Moreover, testosterone treatment showed lipid profile amelioration $^{(31)}$.

Meanwhile, stressed male rats revealed significantly high plasma estrogen level. The low testosterone level and the high estrogen level suggest the reversal of the hormonal pattern following stress in favor of feminine pattern which could be accused of the abnormal lipid profile in the male stressed group.
However, in stressed females the high plasma testosterone level could contribute in the elevated plasma levels of TC and LDL-C. In agreement, a study observed by Wickramatilake et al. ${ }^{(32)}$ observed that TC was associated positively with testosterone level and HDL-C was negatively associated with testosterone level. Echiburú et $a l .{ }^{(33)}$ reported that hyperandrogenism in females may lead to abnormal lipoprotein profile by acting directly at the liver. In a previous study, Fruzzetti et $a .^{(34)}$ mentioned that hyperandrogenism in females is a highly positive risk factor for dyslipidemic changes. This could explain the disturbed lipid profile in female inspite of the significantly increased estrogen level.

Regarding glycemic parameters, hyperglycemia, decreased uptake of glucose by the diaphragm and increased output of glucose by the kidneys observed in stressed male rats could be explained by the existing hypoinsulinemia.

This effect could be explained according to the study by $\mathrm{MCEwen}^{(35)}$ by reduction in insulin secretion and excess secretion of anti-insulin hormones e.g. cortisol and thyroxin. Also, in a previous study, Kioukia et al. ${ }^{(36)}$ reported that chronic mild immobilization enhances secretion of releasing hormones from the anterior pituitary that influence the function of the thyroid gland and the resulting hyperthyroidism was found to worsen blood glucose control and increase insulin requirements. Hyperglycemia could, also, be attributed to gluconeogenesis, assumed to be induced from glycerol supplied by the lipolytic effect of stress ${ }^{(37)}$.

The reduction of plasma testosterone in stressed male rats could be implicated in hyperglycemia. This view is based on the study of Ahmed ${ }^{(11)}$ which 
attributed stress induced hyperglycemia to testosterone lack that promoted cell surface receptor defective glucose transport mechanism, in which phosphorylation of protein kinase B (Akt) and expression of glucose transporter-4 were included. In addition, castration led to impaired glucose oxidation with associated reduction in insulin receptor expression in liver, skeletal muscle and adipose tissue ${ }^{(38)}$.

In stressed females, the observed hyperglycemia that developed upon exposure to immobilization stress could be attributed to dysfunction of B-cell of pancreas as shown by decreased HOMA-B and decreased insulin secretion. Such decline in pancreatic function could be explained by pancreatic islets apoptosis as confirmed by the high Caspase- 3. The oxidative stress state in stressed female group could be supposed to contribute in pancreatic cell injury via direct effect of immobilization stress and indirect via excess testosterone. Such view is in consistence with Liu et $a l .^{(39)}$ showed that excess testosterone in female mice may induce oxidative stress through binding of androgen to its receptor on mononuclear cells. Moreover, women with hyperandrogenism were found to induce generalized oxidative stress ${ }^{(40)}$ and malfunction of B-cell ${ }^{(41)}$.

The observed sex difference in glucose and lipid parameters upon exposure to stress, with females displaying less abnormal glucose and lipid profile than males is assumed to be attributed to the beneficial role of estrogen. In the stressed females of the present study, plasma estrogen level was significantly increased to almost 5 times its value in the unstressed females. It seems that compensatory mechanisms lead to the elevation of estrogen as a line of defense and an attempt by which females could face, buffer and counteracts the injurious effect of stress. However, this elevated estrogen did not totally prevent the effect of stress which imposed hyperlipidemic and glycemic insults that were less than in the male group.

In support to the proposed protective metabolic role of estrogen the study by $\operatorname{Carr}^{(42)}$ reported that estrogens share in metabolic regulation, and that estrogen reduction has extra-reproductive effects including metabolic rate reduction, central adiposity, dyslipidemia, and aggravating metabolic syndrome.

Lucas et al. ${ }^{(43)}$ reported that estrogen improves lipid profile. Fouad and Dahhan ${ }^{(44)}$ observed that degradation of cholesterol and reduction of serum $\mathrm{Tg}$ level is accelerated by estrogen by inducing the use of lipid as fuel. Tessier et al. ${ }^{(45)}$ reported that the effect of estrogen on the maintenance of fat distribution by increasing usage of lipids as a source of energy, reducing the abdominal fat through stimulation of muscle fatty acid oxidation and inhibition of hepatic lipogenesis via peroxisome proliferator-activated receptor (PPAR) and by enhancing lipoprotein lipase (LPL) expression. Estrogen also elevates the oxidative capacity of the muscle by regulation of acyl-CoA oxidase and different uncoupling proteins (UCP2UCP3), that fasten fatty acid uptake preventing accumulation of lipids ${ }^{(46)}$. Therefore, estrogen promotes fat oxidation via muscle AMPK (Adenosine monophosphate kinase) phosphorylation as reported by Beckett et al. ${ }^{(46)}$ and inactivation of malonyl-CoA by elevating carnitine palmitoyl transferase affinity as observed by Alaynick ${ }^{(47)}$ and Cladera et al. ${ }^{(48)}$. 
In addition, estrogen was reported to promote insulin action either directly through actions on insulin-dependent tissues or indirectly by regulating oxidative stress, which participate in insulin resistance. Estrogen receptor alpha (ER $\alpha)$ in skeletal muscle is believed to orchestrate insulin signaling and GLUT4 expression ${ }^{(49)}$. Also, by reducing inflammation ${ }^{(50)}$. ER $\alpha$ knockout mice are more susceptible to oxidative stress that induces apoptosis of beta cells of pancreas ${ }^{(51)}$. Furthermore, estrogen treatment retrive the insulin sensitivity and glucose tolerance in mice fed high fat diet, an effect that was abscent in ER $\alpha$-deficient mice ${ }^{(52)}$.

In male stressed rats, the disturbed oxidant antioxidant state which is in favor of increased oxidative marker MDA and decreased antioxidant defense denoted by low TAC could lead to testicular structure damage and dysfunction, thus providing explanation for the low testosterone level observed in our study. This view is supported by the studies of Manna et al. ${ }^{(53)}$, Kirk et al. ${ }^{(54)}$ and Lutgendorff et al. ${ }^{(55)}$.

In consistence, nitric oxide free radicals were found to lead induction of downregulation of testicular steroidogenesis ${ }^{(56)}$. In addition, Ghosh et al. ${ }^{(57)}$ mentioned that the membranes of testis contains excess amount of polyunsaturated fatty acids leading to its susceptiblity to oxidative stress and MDA, affecting the activity of enzymes involved in testicular steroidogenesis. Moreover, Manna et al. ${ }^{(53)}$ observed that oxidative stress induced by swimming exercise lead to reduction of testicular $3 \beta$-hydroxysteroid dehydrogenase and $17 \beta$-hydroxysteroid dehydrogenase activities that contribute in testosterone synthesis.

Also, increased secretion of glucocorticoids during stress, could be another mechanism for testosterone reduction on stress exposure. This occurs by a glucocorticoid receptor-mediated pathway, where glucocorticoids suppress Leydig cell function ${ }^{(58)}$. It has been observed that glucocorticoids inhibit enzymes involved in testicular steroidogenesis, such as NADPH-P450 reductase, P450c 17 (17 $\alpha$-hydroxylase and 17, 20lyase) and $3 \beta$-hydroxysteroid dehydrogenase ${ }^{(58)}$. Also, induce Leydig cells apoptosis on exposure to excess glucocorticoids ${ }^{(59)}$.

Furthermore, stress induced-endogenous opioids release is assumed to affect testosterone secretion. Stress stimulates secretion of corticotropin releasing factor (CRF) and $\beta$ endorphins that mediate suppression of the hypothalamic-pituitary-gonad (HPG) $\operatorname{axis}^{(60)}$. Moreover, Marquez et al. ${ }^{(61)}$ observed that this stress induced suppressive effect was declined with the opioid antagonist "Naltrexone".

In addition, reduction in testosterone in stressed male rats could be explained by deteriorated testicular blood flow. Stimulation of the sympathetic nerves or injection of catecholamines was found to lead to vasoconstriction, reducing testicular blood flow (62).

However, the significant increase in plasma estrogen level in stressed male rats could be attributed to increased activity of aromatase enzyme, that converts androgens to estrogens ${ }^{(63)}$. Borrás et al. ${ }^{(64)}$ reported that the activity of this enzyme increases in men on exposure to stress.

In stressed female rats the significant increase of plasma estrogen and testosterone could be attributed to hypothalamic-pituitary-adrenal (HPA) axis activation by stress leading to the release of glucocorticoid hormones as reported by the study 
of $M c E w e n^{(35)}$ which mentioned that, ACTH also acts on the zona reticularis, releasing androgens that could be transformed into estron or testosterone, that can be then changed partially to estradiol.

On the contrary to the present findings, Whirledge and Cidlowski ${ }^{(65)}$ found that chronic stress decreases sex hormones. Kirby et al. ${ }^{(66)}$ showed that immobilization stress either acute or chronic could up-regulate the expression of Rfamide- related peptide (RFRP in the dorsomedial hypothalamus (DMH), a mammalian ortholog to gonadotrophin inhibitory hormone, of adult male rats and that this increase in RFRP is associated with inhibition of downstream HPG activity and adrenalectomy blocked the stressinduced increase in RFRP expression. The authors observed that glucocorticoids (GCs) receptors were expressed on 53\% of RFRP cells, indicating the possibility of involvement of adrenal GCs in mediating the stress effect by its direct action on RFRP cells.

For control and stressed female rats plasma testosterone is significantly lower while plasma estrogen is significantly higher than the corresponding male groups which is a normal physiological finding.

In rats of both sexes, exposure to stress promoted significant decrease in the TAC as compared with their respective controls. Meanwhile, significant elevation of plasma MDA was detected only in stressed males compared to control male group and significant elevation of plasma nitrites was observed only in stressed females compared with control female group. These findings denote increased production of free radicals and occurrence of oxidative stress which is in accordance with the study of $Y u^{(67)}$ which reported that stress causes the production of many free radicals, which react with proteins, lipids, carbohydrates, and nucleic acids, lead to the development of various pathologies as reported by Stojiljković et al. ${ }^{(68)}$. Zafir and Banu ${ }^{(69)}$ investigated that oxidative stress induced by the administration of corticosterone for a long time is comparable to that induced by a psychological stressor, proving the involvement of stress hormones in the restraint stress induced oxidative damage. Earlier, McIntosh et al. ${ }^{(70)}$ reported that glucocorticoids decrease the activity of SOD and glutathione peroxidase (GPx).

In stressed female rats, although there was a significant decrease in plasma TAC when compared with control females, it was significantly increased compared to stressed male rats. This finding indicates the less affection of female rats than male rats exposed to stress that may be related to the protective role of estrogen in females. The apparent significantly elevated estrogen displayed by stressed female rats that seems to be a trial to oppose oxidative stress effect, confirm this explanation.

Previously, Tupikowska ${ }^{(71)}$ reported that apart from its main hormonal effect, estradiol has two mechanisms of antioxidant action. One of them is because of the hydroxyphenolic structure of their molecule. Estradiol donates hydrogen from its phenolic hydroxyl group to lipid peroxides what results in the termination of the chain reactions of membrane phospholipids, which are the key reactions in cell destruction. Estradiol, also, suppresses oxidative modulation of LDL that lead to atherogenesis. The other mechanism of antioxidative action of estradiol is probably 
associated with its stimulatory effect on natural cellular antioxidant enzymes. Borrás et al. ${ }^{(64)}$ reported that estrogens increased expression of the antioxidant enzymes via intracellular signaling pathways and prevent the production of reactive oxygen species.

It could, thus, be concluded that chronic immobilization stress imposes hyperglycaemia and dyslipidemia in both males and females, however, its impact was greater in males. The altered sex hormonal pattern together with the lowered antioxidant defenses could be contributory mechanisms in such sex difference.

\section{References:}

1. Priyadarshini S and Aich P: Effects of Psychological Stress on Innate Immunity and Metabolism in Humans: A Systematic Analysis. PLoS ONE; 7(9):e43232, 2012.

2. Stinnett GS and Seasholtz AF: Stress and emotionality. In: Encyclopedia of Behavioral Neuroscience. 1st edition. Koob GF, Le Moal M and Thompson RF (eds), pp. 316-321, Elsevier, United States of America, 2010.

3. Sandifer PA, Knapp LC, Collier TK, Jones AL, Juster RP, Kelble CR, Kwok RK, Miglarese JV, Palinkas LA, Porter DE, Scott GI, Smith LM, Sullivan WC, Sutton-Grier AE: A conceptual model to assess stress-associated health effects of multiple ecosystem services degraded by disaster events in the Gulf of Mexico and elsewhere. GeoHealth; 1(1):17-36, 2017.

4. Nylén EC, Lindfors $P$, Ishäll L, Göransson S, Aronsson G, Kylin C, Sverke M: A pilot- study of a worksite based participatory intervention program: Its acceptability and short-term effects on work climate and attitudes in human service employees. Work; 56(4):625-636, 2017.

\section{Pitocco D, Zaccardi F, Enrico Di Stasio E,} Romitelli F, Santini SA Zuppi C, Ghirlanda GG: Oxidative Stress, Nitric Oxide, and Diabetes. Review of Diabetic Studies; 7(1): 15-25, 2010.

6. Storz P: Reactive oxygen species in tumor progression. Frontiers in bioscience; 10:1881-1896, 2005.

7. Madamanchi NR, Vendrov A, Runge MS: Oxidative stress and vascular disease. Arteriosclerosis, Thrombosis, and Vascular Biology; 25(1):29-38, 2005.

8. Bashan N, Kovsan J, Kachko L, Ovadia H, Rudich A: Positive and negative regulation of insulin signaling by reactive oxygen and nitrogen species. Physiological Reviews; 89(1):27-71, 2009.

9. Pantzaris MC, Loukaides GN, Ntzani EE, Patrikios IS: Omega-3 and omega-6 fatty acids with vitamins (PLP10) in relapsing remitting multiple sclerosis: a randomised, double-blind, placebo-controlled proof-ofconcept clinical trial. BMJ Open; 3(4): e002170, 2013.

10. Verma R, Balhara YP, Gupta CS: Gender differences in stress response: Role of developmental and biological determinants. Industrial psychiatry journal; 20(1): 4-10, 2011.

11. Ahmed MA: Role of Testosterone in Glucose Homeostasis in Immobilization Stressed 
Rats. Journal of American Science; 8(1):628-638, 2012.

12. Diab FM: Studies on the physiological responses to stress of restraint. M.D. Thesis, Physiology Department, Faculty of Medicin, Ain Shams University, 1995.

13. Nascimento AF, Sugizaki MM, Leopoldo AS, Lima-Leopoldo AP, Nogueira CR, Novelli EL, Padovani CR, Cicogna AC: Misclassification probability as obese or lean in hypercaloric and normocaloric diet. Biological research; 41(3): 253-259, 2008.

14. Trinder P: Determination of Blood Glucose Using 4- Amino phenazone as oxygen acceptor. Journal of Clinical Pathology; 22(2):246, 1969.

15. Friedewald WT, Levy RI, Frederickson DS: Estimation of the concentration of lowdensity lipoprotein cholesterol in plasma, without use of the preparative ultracentrifuge. Clinical Chemistry; 18(6): 499-502, 1972.

16. Malaspina JP, Bussière $H$, Le Calve G: The total cholesterol/HDL cholesterol ratio: a suitable atherogenesis index. Atherosclerosis; 40(3-4):373-375, 1981.

17. Matthews DR, Hosker JP, Rudenski AS, Naylor BA, Treacher DF, Turner RC: Homeostasis model assessment: insulin resistance and beta-cell function from fasting plasma glucose and insulin concentrations in man. Diabetologia; 28(7):412-419, 1985.

18. Saleh NK and Saleh HA: Olive oil improved the impairment of in vivo insulin- stimulated glucose uptake by diaphragm in ovariectomized female Wistar rats. Exp. Gerontol.; 45(12):964-969, 2010.

19. Randall HM: Metabolic and functional effects of acute renal ischemia in dog kidney slices. American Journal of Physiology; 223(4): 756-762, 1972

20. Suvarna SK, Layton C, Bancroft JD: Bancroft's theory and practice of histological techniques, $7^{\text {th }}$ edition, Churchill Livingstone, El Sevier: 203; 500504, 2013.

21. Macfarlane DP, Forbes S, Walker BR: Glucocorticoids and fatty acid metabolism in humans: fuelling fat redistribution in the metabolic syndrome. Journal of Endocrinology; 197(2):189-204, 2008.

22. Gilbert ER and Liu D: Epigentics: the missing link to understanding beta-cell dysfunction in the pathogenesis of type 2 diabetes. Epigenetics; 7(8): 841-852, 2012.

23. Bardini G, Rotella CM, Giannini S: Dyslipidemia and Diabetes: Reciprocal Impact of Impaired Lipid Metabolism and Beta-Cell Dysfunction on Micro- and Macrovascular Complications. Review of Diabetic Studies; 9(2-3): 82-93, 2012.

24. Rabasa C and Dickson SL: Impact of stress on metabolism and energy balance. Current Opinion in Behavioral Sciences; 9:71-77, 2016.

25. Duncan RE, Ahmadian M, Jaworski K, Nagy ES, Sul HS: Regulation of Lipolysis in Adipocytes. Annual Review of Nutrition; 27: 79-101, 2007.

26. Niaura R, Stoney CM, Herbert PN: Lipids in psychological research: the last decade. Biological Psychology; 34(1): 1-43, 1992. 
27. Djurhuus $\mathrm{CB}$, Gravholt $\mathrm{CH}$, Nielsen $\mathrm{S}$, Mengel A, Christiansen JS, Schmitz OE, Møller N: Effects of cortisol on lipolysis and regional interstitial glycerol levels in humans. American Journal of Physiology: Endocrinology and Metabolism; 283(1):E172-177, 2002.

28. Brindley DN, McCann BS, Niaura $R$, Stoney CM, Suarez EC: Stress and lipoprotein metabolism: modulators and mechanisms. Metabolism; 42(1):3-15, 1993.

29. Kohan AB, Howles PN, Patrick TS: Methods for studying rodent intestinal lipoprotein production and metabolism. Current Protocols in Mouse Biology; 2:219-230, 2012.

30. Haffner SM, Miettinen $H$, Karhapaa $P$, Mykkänen L, Laakso M: Leptin concentrations, sex hormones, and cortisol in nondiabetic men. The Journal of Clinical Endocrinology and Metabolism; 82(6):1807-1809, 1997.

31. Malkin CJ, Pugh PJ, Jones RD, Kapoor D, Channer KS, Jones TH: The effect of testosterone replacement on endogenous inflammatory cytokines and lipid profiles in hypogonadal men. Journal of Clinical Endocrinology and Metabolism; 89(7):3313-3318, 2004.

32. Wickramatilake CM, Mohideen MR, Pathirana C: Association of metabolic syndrome with testosterone and inflammation in men. Annales d'Endocrinologie; 76(3):260-263, 2015.

33. Echiburú B, Bravo FB, Maliqueo M, De Guevara AL, Gálvez C, Crisosto N, SirPetermann T: CAG repeat polymorphism of androgen receptor gene and $X$ chromosome inactivation in daughters of women with polycystic ovary syndrome (PCOS): relationship with endocrine and metabolic parameters. Gynecological Endocrinology; 28(7):516-520, 2012.

34. Fruzzetti F, Perini D, Lazzarini V, Parrini D, Genazzani AR: Adolescent girls with polycystic ovary syndrome showing different phenotypes have a different metabolic profile associated with increasing androgen levels. Fertility and Sterility; 92(2):626-634, 2009.

35. McEwen BS: Central effects of stress hormones in health and disease: Understanding the protective and damaging effects of stress and stress mediators. European Journal of Pharmacology; 583(23):174-185, 2008.

36. Kioukia N, Bekris S, Antoniou $\mathrm{K}$, Papadopoulou-Daifoti Z, Christofidis I: Effects of chronic mild stress (CMS) on thyroid hormone function in two rat strains. Psychoneuroendocrinology; 25(3):247-257, 2000.

37. Marik PE and Bellomo R: Stress hyperglycemia: an essential survival response. Critical Care; 17(2): 305, 2013.

38. Muthusamy $T$, Dhevika $S$, Murugesan $P$, Balasubramanian K: $\quad$ Testosterone deficiency impairs glucose oxidation through defective insulin and its receptor gene expression in target tissues of adult male rats. Life Sciences; 81(7):534-542, 2007.

39. Liu S, Navarro G, Mauvais-Jarvis F: Androgen Excess Produces Systemic 
Oxidative Stress and Predisposes to $\beta$-Cell Failure in Female Mice. PLoS One; 5(6): e11302, 2010.

40. González F, Rote NS, Minium J, Kirwan JP: Reactive oxygen species-induced oxidative stress in the development of insulin resistance and hyperandrogenism in polycystic ovary syndrome. Journal of Clinical Endocrinology and Metabolism; 91(1):336-340, 2006.

41. Goodarzi MT, Navidi AA, Rezaei M, Babahmadi-Rezaei H: Oxidative damage to DNA and lipids: correlation with protein glycation in patients with type 1 diabetes. Journal of Clinical Laboratory Analysis; 24(2):72-76, 2010.

42. Carr MC: The emergence of the metabolic syndrome with menopause. Journal of Clinical Endocrinology and Metabolism; 88(6):2404-2411, 2003.

43. Lucas EA, Wild RD, Hammond LJ, Khalil DA, Juma S, Daggy BP, Stoecker BJ, Arjmandi BH: Flaxseed improves lipid profile without altering biomarkers of bone metabolism in postmenopausal women. Journal of Clinical Endocrinology and Metabolism; 87(4):1527-1532, 2002.

44. Al Dahhan Fh, Al Naama LM, Disher A: Lipid profile and Menopausal status. AlKindy College Medical Journal; 4(1): 8-12, 2008.

45. Tessier S, Riesco E, Lacaille M, Pérusse F, Weisnagel J, Doré J, Mauriège P: Impact of walking on adipose tissue lipoprotein lipase activity and expression in pre- and postmenopausal women. Obesity Facts; 3(3):191-199, 2010.
46. Beckett T, Tchernof A, Toth MJ: Effect of ovariectomy and estradiol replacement on skeletal muscle enzyme activity in female rats. Metabolism; 51(11):1397-1401, 2002.

47. Alaynick WA: Nuclear receptors, mitochondria and lipid metabolism, Mitochondrion; 8(4): 329-337, 2008.

48. Cladera AE, Lladó I, Gianotti M, Proenza AM: Retroperitoneal white adipose tissue mitochondrial function and adiponectin expression in response to ovariectomy and 17ß-estradiol replacement. Steroids; 77(6): 659-665, 2012.

49. Barros RPA, Gabbi C, Morani A, Warner M, Gustafsson JA: Participation of ERa and ER $\beta$ in glucose homeostasis in skeletal muscle and white adipose tissue. American Journal of Physiology. Endocrinology and Metabolism; 297(1): E124-133, 2009.

50. Ribas V, Nguyen MA, Henstridge DC, Nguyen AK, Beaven SW, Watt MJ, Hevener AL: Impaired oxidative metabolism and inflammation are associated with insulin resistance in ER $\alpha$-deficient mice. American Journal of Physiology. Endocrinology and Metabolism; 298(2): 304-319, 2010.

51. May CL, Chu K, Hu M, Ortega CS, Simpson ER, Korach KS, Tsai MJ, Mauvais-Jarvis MF: Estrogens protect pancreatic $\beta$-cells from apoptosis and prevent insulin-deficient diabetes mellitus in mice. Proceedings of the National Academy of Sciences of the United States of America; 103(24): 9232-9237, 2006.

52. Riant E, Waget A, Cogo H, Arnal JF, Burcelin R, Gourdy P: Estrogens protect 
against high-fat diet-induced insulin resistance and glucose intolerance in mice. Endocrinology; 150(5): 2109-2117, 2009.

53. Manna I, Jana K, Samanta PK: Intensive Swimming Exercise-Induced Oxidative Stress and Reproductive Dysfunction in Male Wistar Rats: Protective Role of $\alpha$ Tocopherol Succinate. Canadian Journal of Applied Physiology; 29(2): 172-185, 2004.

54. Kirk GR, White JS, McKie L, Stevenson M, Young I, Clements WD, Rowlands BJ: Combined antioxidant therapy reduces pain and improves quality of life in chronic pancreatitis. Journal of Gastrointestinal Surgery; 10(4): 499-503, 2006.

55. Lutgendorff F, Trulsson LM, van Minnen LP, Rijkers GT, Timmerman HM, Franzén LE, Gooszen HG, Akkermans LM, Söderholm JD, Sandström PA: Probiotics enhance pancreatic glutathione biosynthesis and reduce oxidative stress in experimental acute pancreatitis. American Journal of Physiology. Gastrointestinal and Liver Physiology; 295(5): G1111-1121, 2008.

56. Kostic TS, Andric SA, Maric D, Kovacevic RZ: Inhibitory Effects of Stress-Activated Nitric Oxide on Antioxidant Enzymes and Testicular Steroidogenesis. Journal of Steroid Biochemistry and Molecular Biology; 75(4-5): 299-306, 2000.

57. Ghosh D, Das UB, Ghosh S, Mallick M, Debnath I: Testicular Gametogenic and Steroidogenic Activities in Cyclophosphamide Treated Rat: A Correlative Study with Testicular Oxidative
Stress. Drug and Chemical Toxicology; 25(3): 281-292, 2002.

58. Dong Q, Salva A, Sottas CM, Niu E, Holmes M, Hardy MP: Rapid Glucocorticoid Mediation of Suppressed Testosterone Biosynthesis in Male Mice Subjected to Immobilization. Journal of Andrology; 25(6): 973-981, 2004.

59. Gao HB, Tong MH, Hu YQ, Guo QSG, Hardy MP: Glucocorticoid Induces Apoptosis in Rat Leydig Cells. Endocrinology; 143(1): 130-138, 2002.

60. Vaccarino AL and Kastin AJ: Endogenous Opiates: 2000. Peptides; 22(12): 2257-2328, 2000.

61. Retana-Márquez $\mathrm{S}$, Bonilla-Jaime $\mathrm{H}$, Vázquez-Palacios G, Martínez-García R: Naltrexone Effects on Male Sexual Behavior, Corticosterone, and Testosterone in Stressed Male Rats. Physiology and Behavior; 96(2): 333-342, 2009.

62. Kraut A, Barbiro-Michaely E, Mayevsky A: Differential Effects of Norepinephrine on Brain and Other Less Vital Organs Detected by a Multisite Multiparametric Monitoring System. Medical Science Monitor; 10(7): RB215-220, 2004.

63. Capellino S, Straub RH, Cutolo M: Aromatase and regulation of the estrogento-androgen ratio in synovial tissue inflammation: common pathway in both sexes. Annals of the New York Academy of Sciences; 1317:24-31, 2014.

64. Borrás C, Gambini J, López-Grueso LR, Pallardó FV, Viña J: Direct antioxidant and protective effect of estradiol on isolated 
mitochondria. Biochimica et Biophysica Acta; 1802(1):205-211, 2010.

65. Whirledge $S$ and Cidlowski JA:

Glucocorticoids, Stress, and Fertility. Minerva Endocrinologica; 35(2): 109-125, 2010.

66. Kirby ED, Geraghty AC, Ubuka T, Bentley GE, Kaufer D: Stress increases putative gonadotropin inhibitory hormone and decreases luteinizing hormone in male rats. Proceedings of the National Academy of Sciences of the United States of America; 106(27):11324-11329, 2009.

67. Yu BP: Cellular defenses against damage from reactive oxygen species. Physiological Reviews; 74(1):139-162, 1994.

68. Stojiljković V, Todorović A, Kasapović J, Pejić S, Pajović SB: Antioxidant enzyme activity in rat hippocampus after chronic and acute stress exposure. Annals of the New York Academy of Sciences; 1048:373-376, 2005.

69. Zafir A and Banu N: Induction of oxidative stress by restraint stress and corticosterone treatments in rats. Indian Journal of Biochemistry and Biophysics; 46(1):53-58, 2009.

70. McIntosh LJ: Glucocorticoids may alter antioxidant enzyme capacity in the brain: baseline studies. Brain Research; 791(1-2): 209-214, 1998.

71. Bednarek-Tupikowska G: Antioxidant properties of estrogens. Ginekologia polska; 73(1):61-67, 2002. 